\section{Seis características das mortes violentas no Brasil}

\author{
Maria Cecília de Souza Minayo*
}

Este texto reúne algumas informações que evidenciam certas peculiaridades da violência no Brasil, utilizando-se indicadores de mortalidade, que são considerados, mundialmente, os dados mais confiáveis para analisar esse problema (MINAYO, 2008). Para fundamentar essa reflexão, são usadas duas categorias fundamentais: a de causas externas e a de violência.

O termo causas externas é empregado, pela área de saúde, para se referir à mortalidade por: (a) homicídios e suicídios, agressões físicas e psicológicas; (b) acidentes de trânsito, transporte, quedas, afogamentos e outros; (c) lesões e traumas provocados também por esses eventos. A categoria causas externas é operativa e tem servido, há mais de dois séculos, para as organizações internacionais de saúde e sociais efetuarem perfis, comparações e, assim, emitirem observações e sugestões aos governos nacionais e locais a respeito do fenômeno social da violência que provoca a morte, podendo então ser alvo de intervenções e comparações.

Já a violência é uma questão social que ocorre nas inter-relações humanas e nas suas criações (Estado, organizações sociais, instituições, etc.), constituindo, portanto, objeto de estudo e interpretações por parte da filosofia, da história, das ciências políticas, do direito, entre outros. É difícil definir a violência; no entanto, os muitos estudos hoje existentes permitem mapeá-la como um fenômeno humano, social e histórico que se traduz em atos realizados, individual ou institucionalmente, por pessoas, famílias, grupos, classes e nações, visando prejudicar, ferir, mutilar ou matar o outro, física, psicológica e até espiritualmente. No conceito de violência está incluída a ideia da omissão, que aceita e naturaliza maus tratos ao outro individual ou coletivo. A violência, além de provocar forte impacto sobre as taxas de morbimortalidade, apresenta importantes repercussões econômicas para a área de saúde pública (BRASIL, 2001), para as famílias e para a sociedade em geral. Neste estudo, buscase apresentar dados de causas externas e estender a compreensão das cifras por meio de uma análise do significado das várias formas de violência.

No Brasil, na década de 1990, mais de um milhão de pessoas morreram vítimas de violência e acidentes: cerca de 400 mil por homicídios, 310 mil em acidentes de trânsito e 65 mil por suicídios, estando o restante distribuído em vários tipos de acidentes, como é o caso dos afogamentos, que em muitas circunstâncias podem estar ocultando atos de suicídio. Na primeira década dos anos 2000, caminha-se pela mesma trilha, havendo uma leve tendência de queda nos últimos cinco anos. Os três fenômenos - acidentes, violências e suicídios - constituem uma rubrica que se alterna entre o segundo e o terceiro lugar no quadro geral da mortalidade no país e é a primeira causa de óbito da população de 5 a 49 anos. Neste texto apresentam-se algumas características das mortes violentas no Brasil, tomando-se por base dados do período de 1980 a 2005.

\section{9 característica: elevadas e crescentes taxas nos últimos 25 anos}

Chama atenção a persistência das elevadas taxas de mortalidade por causas externas ao longo de duas décadas e meia. Os óbitos por homicídios e por acidentes de trânsito são os principais elementos que conformam o quadro das mortes violentas. A participação das causas externas na mortalidade geral no país aumentou de $11 \%$ para $15 \%$ no período aqui tratado. Ocupando ora

\footnotetext{
* Pesquisadora titular da Fundação Oswaldo Cruz, pesquisadora de carreira do CNPQ, editora da Revista Ciência \& Saúde Coletiva e assessora do presidente do BNDES para avaliação de projetos.
} 
o segundo ora o terceiro lugar, esse fenômeno revela a gravidade da situação social que deve ser analisada, para ser compreendida, no contexto e na história dos problemas sociais do Brasil.

\section{2a característica: diferenciações entre os municípios brasileiros}

Em 2000, do total de 5.561 municípios brasileiros, em 1.802 não ocorreu nenhum acidente de trânsito fatal, em 2.633 deles não houve sequer um homicídio e em 3.382 não foi notificada qualquer morte por suicídio. Essa diferenciação interna é uma peculiaridade que passa despercebida do público em geral. Quando se fala de violência, a população está acostumada a ter notícia do que acontece no Rio de Janeiro e em São Paulo, passando a imaginar que o mesmo ocorre no país inteiro e de forma homogênea. É importante ressaltar que as diferenciações não devem esconder o fato de que existem violências nos municípios que apresentam taxas zero de homicídios, suicídios e mortes no trânsito. Em qualquer localidade do país acontecem várias formas de violência, como lembra a Organização Mundial de Saúde em seu documento oficial: "Há muito mais violência ocorrendo de forma invisível nos lares, nos locais de trabalho, nas instituições médicas e sociais criadas para cuidar das pessoas. Muitas são demasiadamente jovens, fracas e doentes para se protegerem. Outras são forçadas por convenções ou pressões sociais a se manterem em silêncio" (WHO, 2002, p.3).

Essas sábias palavras estão de acordo com a ideia de que a violência, sendo um fenômeno social, está presente em qualquer parte do mundo onde há seres humanos convivendo, sob manifestações de opressão, dominação, abuso de poder e agressões físicas, emocionais e espirituais. Mais do que isso, os vários tipos de violência (visíveis, públicas ou privadas) se potencializam uns aos outros. Existe uma articulação entre problemas aparentemente sem importância ou mesmo naturalizados - como é o caso de castigos físicos e maus tratos como meio pedagógico - e problemas muito mais complexos, tais como fuga de crianças e jovens de seus lares ou das escolas e seu aliciamento pelas quadrilhas criminosas. Há vários tipos de violência cultural que ocorrem no país e constituem hábitos e costumes de longa duração: agressões conjugais; abusos físicos, psicológicos e sexuais; negligências; trabalho em idade precoce no caso da infância e da adolescência; entre outros. É importante saber também que as manifestações da violência cultural atingem de forma diferenciada meninos e meninas, homens e mulheres, jovens e velhos.

\section{3a característica: dispersão espacial dos acidentes de trânsito e de transporte}

Ao contrário dos homicídios que estão concentrados em determinados espaços sociais, uma característica fundamental das mortes por acidentes de trânsito e de transporte é o fato de elas ocorrerem de forma dispersa pelo território nacional, com forte inflexão em muitos municípios de pequeno e médio portes.

As mortes por acidentes acontecem, sobretudo, nas localidades cortadas por vias expressas, onde há estradas em má conservação, muito movimento e pistas duplas, e no interior de cidades em crescimento, onde os veículos circulam sem lei, sem segurança e sem sinalização precisa. Na maioria desses municípios faltam reconhecimento da gravidade do problema e estratégias de prevenção e repressão aplicadas de forma rotineira e permanente, visando a prevenção das mortes e incapacitações.

De 1998 até 2003, por causa da nova legislação contida no Código de Trânsito promulgado no final de 1997, houve uma queda expressiva no número e nas taxas de morte no trânsito no país. A partir de então, a curva recomeçou a evidenciar, novamente, tendência de crescimento. A análise por grupos de idade mostra que os jovens são os mais vulneráveis, mas tem havido, nos últimos anos, incremento de mortes na população idosa. Esse aumento é caracterizado, sobretudo, por atropelamentos e quedas nas vias públicas e nos veículos de uso coletivo. 
É importante ressaltar que, na sociedade contemporânea, as mortes no trânsito não comovem tanto como os homicídios, ou os óbitos por câncer ou Aids, por exemplo.

$\mathrm{O}$ aumento crescente das motos em circulação, sem a devida correspondência de normas claras para sua movimentação, tanto em cidades do interior como nas metrópoles, constitui um problema a mais para a mobilidade social. Estudos sobre realidades locais e de âmbito nacional vêm mostrando o incremento de mortes e incapacitações devidas a acidentes com motos, em proporções muito mais elevadas do que com outros veículos.

Assinala-se, também, um fenômeno que passou a ser notificado e relatado recentemente: o envolvimento de motoqueiros e seus caronas em assaltos a mão armada em grandes regiões metropolitanas. Essa prática vem sendo facilitada pela rápida mobilidade e pelo uso de capacetes (que deveriam proteger os motoristas) que dificultam a identificação dos criminosos.

\section{4a característica: taxas baixas, mas crescimento de suicídios de idosos}

Diferentemente da situação relacionada aos acidentes de transporte e aos homicídios, para a população em geral, o Brasil mantém taxas relativamente baixas de suicídio, constantes em toda a série histórica analisada. No entanto, é importante observar duas peculiaridades nas mortes por autodestruição: prevalência dos suicídios de homens em todas as faixas de idade; e aumento desse fenômeno na população idosa, sobretudo na segmento acima de 70 anos. Esse último fenômeno vem acompanhando o crescimento ímpar do número de idosos no país nos últimos anos. Altas taxas de suicídio na população idosa já são conhecidas nos países europeus e no Japão, entre outros (CHESNAIS, 1981).

Os estudos da Organização Mundial de Saúde (WHO, 2001; CHESNAIS, 1981) revelam que as intenções de se matar, por parte de pessoas idosas, estão quase sempre relacionadas aos sentimentos de solidão, de impotência social e ao elevado grau de sofrimento provocado por enfermidades degenerativas e depressão. Muitos suicídios têm como causa associada o abandono e outras formas de violência praticadas pelas famílias ou por instituições que deveriam prestar assistência a esses idosos.

\section{5a característica: concentração por gênero, idade e local de moradia}

Os homens são as principais vítimas das violências e dos acidentes, contribuindo com o maior número de mortos e de traumatizados. As mortes de adultos jovens de 25 a 29 anos, por acidentes de transporte, estão localizadas em $29,1 \%$ dos municípios e os óbitos por agressões, em 27,2\%. Existe uma concentração dos homicídios de jovens no país em $10 \%$ dos municípios que abrigam $47 \%$ da população brasileira e onde ocorrem mais de $80 \%$ deles (SOUZA; MINAYO, 2007). Por sua vez, a cada 100 ocorrência por causas externas, 54 envolvem homens, enquanto as mulheres representam 4,4 desse universo - numa razão de 12 para 1. Ou seja, desde a década de 1980 , as taxas de mortalidade por causas externas em geral pouco se alteraram para o sexo feminino. Há sim mudanças na configuração da participação feminina no crime e nos problemas e conflitos sociais, mas não no conjunto da mortalidade por violências (SOUZA; LIMA, 2006).

A mesma concentração das taxas de óbitos por causas externas, observada em relação à população masculina, se encontra também quanto às faixas etárias. Durante os últimos 25 anos, cerca de $70 \%$ de todos os homicídios foram de adolescentes e homens jovens de 10 a 39 anos, em sua maioria pobres, com baixa escolaridade e vivendo nas periferias das regiões metropolitanas das grandes cidades. Nos subgrupos que compõem essa ampla faixa etária, o primeiro lugar corresponde ao de 20 a 24 anos, que disputou essa posição com o de 25 a 29 anos até 1993 e, a partir de então, assumiu a primazia. Embora o segmento de 15 a 19 anos apresente taxas menores, é o que teve maior crescimento $(33,8 \%)$, quando se comparam as médias das taxas dos períodos 2000-2005 e 1980-1985 (SOUZA; MINAYO, 2007). A maior magnitude de mortes vio- 
lentas refere-se à população masculina em comparação com as mulheres; aos jovens em comparação com os adultos; aos pobres em relação aos ricos; e aos moradores das periferias urbanas mais que aos que vivem no campo ou nas áreas abastadas das cidades.

No caso da população jovem e jovem adulta, em todo o período, a Região Sudeste desponta com a que possui as maiores taxas de mortalidade por causas externas, exceto em dois anos, 1982 e 2005, nos quais o Centro-Oeste prepondera. No Sul, observase um persistente crescimento das taxas a partir dos anos 2000. Nas Regiões Norte e Nordeste ocorre também um incremento gradual. Apesar de registrar taxas muito elevadas, a Região Sudeste é a única que apresenta tendência de queda nos últimos anos.

Nas capitais da Região Norte, há um evidente crescimento das taxas em Porto Velho, a partir dos anos 2000, e uma tendência de aumento em Macapá, em oposição à tendência de queda em Manaus, no mesmo período. Nas capitais da Região Nordeste, ressalta-se o crescimento das taxas em João Pessoa, Recife e Maceió (essa última mais intensamente nos anos 2000). No Sudeste existe uma evidente elevação nas taxas em Vitória e Belo Horizonte. Ao contrário, observa-se uma sensível diminuição das mortes por causas externas em São Paulo, principalmente pela queda nas taxas de homicídios. Já no Rio de Janeiro, as taxas permanecem elevadas, apresentando apenas uma discreta tendência de redução. $\mathrm{Na}$ Região Sul existe tendência de elevação das taxas de causas externas em Curitiba e Florianópolis, sobretudo a partir dos anos 2000. No Centro-Oeste, em todas as capitais, as taxas são elevadas (na maioria do período, taxas em torno de 100/100.000) e oscilam sem tendência definida. Brasília mostra uma leve tendência de diminuição nos últimos dois anos.

Quando se consideram as taxas históricas de mortalidade violenta na faixa etária jovem, no grupo dos homens as agressões são a primeira causa de morte durante todo o período analisado e vai assumindo uma importância cada vez maior. Em 1980, essas mortes representavam $28,9 \%$ e, ao final de 2005 , atingiram $56,1 \%$ de todos os óbitos por causas externas. No caso dos acidentes de transporte ocorreu um movimento inverso, porém com bem menos intensidade: passaram de $24,5 \%$, em 1980 , para $23,7 \%$, em 2005. Entre os jovens do sexo masculino essas duas causas específicas, que já eram muito relevantes em 1980, responderam por quase $80 \%$ dos óbitos em 2005 (SOUZA; MINAYO, 2007).

Apesar de não haver mudanças muito visíveis nas tendências das causas externas para as mulheres no período de 1980 a 2005, essa realidade se modificou no caso das mais jovens: em 2005, as causas violentas passaram a representar o primeiro lugar na sua mortalidade geral, significando que o peso de outras causas diminuiu. A primeira subcausa específica nesse conjunto corresponde aos acidentes de transporte, que cresceram $26,4 \%$ no período, passando de $32,2 \%$ para $40,7 \%$ nos óbitos femininos por causas externas, entre 1980 e 2005. Também as agressões tomaram uma posição de maior importância, saindo do 3 ㅇ para o 2o lugar (SOUZA; MINAYO, 2007).

\section{6a característica: concentração das mortes por meio de armas de fogo}

Hoje, em todas as capitais do país, a arma de fogo é o instrumento preferencial para dirimir conflitos e produzir a morte entre as pessoas - sobretudo entre os homens. Atualmente, não se pode falar de homicídio no Brasil e no mundo sem que venha à tona a evidência do envolvimento e da contribuição das armas de fogo, que movimentam um dos maiores mercados da economia global. Os dados da década de 1990, analisados primeiro por Peres (2004) e em seguida por Souza e Lima (2006), sugerem que acima de $60 \%$ dos assassinatos ocorridos em áreas urbanas brasileiras foram cometidos com o uso desses aparatos.

A Organização Mundial de Saúde (WHO, 2001) estimou que 2,3 milhões de mortes violentas no mundo, em 2000 , envolveram armas de fogo, várias centenas de milhares tendo resultado em homicídios, suicídios e óbitos em conflitos bélicos. A 
partir de informações sobre 52 países com rendas altas e médias, a WHO (2001) calculou que cerca de 115.000 pessoas morreram por ferimentos causados por arma de fogo, tomando-se como exemplo apenas um dos anos da década de 1990. Desses óbitos, 79.000 (69\%) foram homicídios e mais de $80 \%$ vitimaram homens, principalmente nas faixas jovens de 15 a 44 anos de idade.

No Brasil há uma tendência de crescimento do uso de armas de fogo pela população: foram registrados 15.460 homicídios por esse meio em 1991; 30.855 em 2000; e 36.081 em 2003, segundo Souza e Lima (2006). Na década de 1990, as armas de fogo tiveram predomínio entre os instrumentos para provocar mortes por violência, nas cinco regiões e em todos os estados, considerando-se tanto as vítimas do sexo masculino como do feminino. Essa contribuição foi maior no Nordeste (sobretudo em Pernambuco) e no Sudeste, especialmente no Rio de Janeiro, estado onde $90 \%$ das mortes violentas são cometidas com o uso da arma de fogo e $70 \%$ dos homicídios são provocados por confrontos entre os traficantes e deles com os policiais. Esse estado continua apresentando a mais elevada taxa de homicídios por armas de fogo do Sudeste, mas São Paulo teve o maior incremento da região (146\%): suas taxas passaram de 10,5 para 25,8 óbitos por 100 mil pessoas.

Na Região Sul, o Rio Grande do Sul lidera e, no Centro Oeste, as taxas cresceram em todos os estados, porém com mais intensidade em Mato Grosso (incremento de $371 \%$ ), passando de 6,1 para 28,9 óbitos por 100 mil pessoas, entre 1991 e 2003. O Distrito Federal possuía as maiores taxas no

\section{Referências}

BRASIL. MINISTÉRIO DA SAÚDE (MS). Política nacional de redução de acidentes e violências. Brasília: Ministério da Saúde, 2001.

CHESNAIS, J. C. Histoire de la violence en Occident de 1800 à nos jours. Paris: Robert Laffont Éditor, 1981. início dos anos 1990, continuando altas para a população masculina, ao longo de todo o período (SOUZA; LIMA, 2006).

Em alguns estados como Amapá, Paraíba, Pernambuco, Alagoas, Espírito Santo e Distrito Federal, a proporção de homicídios por esse meio foi superior a 90\% (SOUZA; LIMA, 2006).

O incremento maior tanto de vítimas como de agressores por armas de fogo ocorreu na população urbana pobre, masculina, jovem e vivendo nas periferias, nas faixas dos 15 aos 19 e dos 20 aos 29 anos. A chance de um homem de 20 aos 29 anos morrer por arma de fogo, hoje no Brasil, é quase 20 vezes maior do que a de uma mulher na mesma idade. Mas aumentaram também as taxas de mortes femininas por esse meio, numa média de $28,4 \%$ para todas as idades; de $42 \%$ dos 15 aos 19 anos; de $15,2 \%$ no grupo de 20 a 29 ; e de $45 \%$ no segmento de 30 a 39 anos (SOUZA; LIMA, 2006).

\section{Considerações finais}

As características das mortes violentas no Brasil aqui apresentadas, e que merecem ser muito mais aprofundadas, não constituem uma mera curiosidade. Elas mostram o quão complexa é a violência brasileira e o quanto é preciso tratá-la na sua especificidade. Com certeza há muito por fazer no processo incessante de tornar científicas as reflexões que se fazem sobre esse fenômeno. No entanto, o pouco que os dados já permitem compreender e interpretar traz elementos importantes para a ação de uma sociedade em processo de democratização, como a brasileira.

MINAYO, M. C. de S. Mortes violentas no Brasil: 1980-2005. Divulgação em Saúde para Debate, v. 41, p. 23-35, 2008.

PERES, M. F. Mortalidade por armas de fogo no Brasil, 1991-2000. Brasília: Ministério da Saúde, WHO/Opas/SAS/NEVUSP, 2005. 
SOUZA, E. R.; LIMA, M. L. Panorama da violência urbana no Brasil e suas capitais. Ciência \& Saúde Coletiva, 11(supl. 1): 1.211-1.222, 2006.

SOUZA, E. R.; MINAYO, M. C. de S. Morbimortalidade de jovens de 15 a 29 anos por violências e acidentes no Brasil: situação atual. Tendências e perspectivas. Brasília: Opas/Claves, 2007 (no prelo).
WHO - World Health Organization. Small arms and global health: Injuries Violence Prevention Department, Non-communicable Diseases and Mental Health. Genève: WHO, 2001.

World report on violence and health. Genève: WHO, 2002.

Recebido para publicação em 23/04/2009. Aceito para publicação em 03/05/2009. 